\title{
Apontamentos para a fundamentação de pesquisa sobre a poesia da tradição oral: ênfases, impasses e perspectivas
}

\author{
Roberto Henrique Seidel* \\ Solange Santana
}

\begin{abstract}
Resumo: No presente estudo, empreende-se discussão Zusammenfassung: In der vorliegenden Arbeit wird no sentido da fundamentação teórica de pesquisa eine Diskussion hinsichtlich der theorethischen acerca da poesia de tradição oral na região da Chapada Fundierung der Forschung der mündlich überlieferten Diamantina, na Bahia. Trata-se de aspectos gerais Dichtung in der Region der Chapada Diamantina, in acerca da diversidade cultural, da oposição fala e dem brasilianischen Bundesland Bahia, durchgeführt. escrita, bem como de questões éticas atinentes a este Untersucht werden folgende Aspekten: kulturelle tipo de pesquisa. Verschiedenheit, die Opposition Sprache-Schrift, sowie charakteristich für diese sorte von Forschung ehtische Fragen.
\end{abstract}

Palavras-chave:poesia oral; cultura popular; história Keywords: mündlich überlieferte Dichtung; oral. Volkskultur; mündlich überlieferte Geschichte.

\section{Introdução}

O presente trabalho tem por objetivo discutir aspectos relevantes para a fundamentação de pesquisa sobre a poesia da tradição oral. O campo de pesquisa é delimitado geograficamente como a região de Andaraí, na Chapada Diamantina, na Bahia. Apesar de ter

\footnotetext{
* Professor adjunto de Teoria da Literatura, no Curso de Letras, na Especialização em Estudos Literários e no Programa de Pós-Graduação em Literatura e Diversidade Cultural - PPGLDC, da Universidade Estadual de Feira de Santana - UEFS. Graduado em Letras Germânicas pela UNISINOS, especialista pela Albert-LudwigsUniversität Freiburg im Breisgau, mestre e doutor em Teoria Literária pela Universidade Federal de Pernambuco - UFPE. Entre outros, publicou: Do futuro do presente ao presente contínuo: modernismo vs. pós-modernismo (São Paulo: Annablume, 2001) e Embates simbólicos: estudos literários e culturais (Recife: Bagaço, 2007). Endereço eletrônico: rhseidel@ig.com.br. - O presente trabalho é uma versão ampliada de comunicação "Poesia oral: estudo de caso de poesias da tradição oral de Andaraí, na Chapada Diamantina", proferida no Espaço de Diálogo "Cultura popular e fronteiras do saber: relações entre história, antropologia e estudos culturais", durante o VI Encontro de História Oral do Nordeste, promovido pela Associação Brasileira de História Oral, Secção Nordeste (ABHO/NE), na Universidade Estadual de Santa Cruz - UESC, em Ilhéus, em maio de 2007.

*** Estudante do Curso de Letras Vernáculas da Universidade Estadual de Feira de Santana - UEFS; pesquisadora de Iniciação Científica voluntária, responsável pelo pré-levantamento junto aos poetas. E-mail: professorasolange@hotmail.com.
} 
sido feito levantamento informal - i. e., recolha de poemas e contato inicial com poetas que podem ser incluídos na categoria da oralidade, visto não terem acesso à difusão impressa de suas produções -, a pesquisa propriamente ainda não foi executada. Isso se dá por conta de este ser um âmbito de pesquisa para o qual se faz necessário uma fase prévia à entrada em campo com o objetivo da recolha de material.

Neste sentido, apresenta-se aqui inicialmente reflexões de ordem geral para a pesquisa de questões atinentes à dita diversidade cultural. Num segundo momento, é indicado um possível lastro de reflexão sobre a poesia de tradição oral. São contemplados ainda aspectos pertinentes à oposição fala e escrita dentro da tradição ocidental e latino-americana. Por último, aborda-se algumas questões de ordem ética que dizem respeito à relação pesquisadorpesquisado.

Com a presente pesquisa, trata-se de discutir esta produção poética a partir de um local teórico inter, senão transdisciplinar, incorporando ao escopo da teoria da literatura e dos estudos culturais ganhos conceptuais oriundos da antropologia, da sociologia, bem como especialmente da historiografia oral, da história social e ambiental. Neste sentido, pretende-se contribuir para a discussão da desconstrução de velhas e o estabelecimento de novas fronteiras para o tratamento de produtos culturais das ditas culturas populares, além do que também enriquecer o próprio desenrolar e a fundamentação futura da pesquisa em andamento.

\section{Diversidade cultural e culturas populares}

Em meados de setembro do ano de 2006, o Brasil ratificou a Convenção da Diversidade Cultural, celebrada em 2005, pela Organização das Nações Unidas para a Educação, a Ciência e a Cultura (Unesco). Esta convenção é encarada, de forma geral, como o primeiro acordo internacional com respeito a garantias de proteção, promoção e reconhecimento da diversidade cultural, sobre o qual há certo consenso em âmbito internacional: são 148 países signatários, com exceção dos Estados Unidos e de Israel. O fato dos Estados Unidos se posicionarem contrários à Convenção é justamente um índice que merece atenção. Se, do ponto de vista da maioria dos países signatários, a convenção é considerada um grande avanço no sentido da preservação das culturas regionais, no sentido da liberdade identitária dos países em condições econômicas desfavoráveis; do ponto de vista dos Estados Unidos - o principal financiador da Unesco -, as trocas e os intercâmbios culturais deveriam ser regidos pelos mesmos princípios que regem os intercâmbios comerciais, ou seja, seriam "as leis do comércio internacional, submetidas às políticas de 
livre-comércio da Organização Mundial do Comércio (OMC)", que deveriam reger os fluxos culturais em âmbito global. Sem pretender aqui perseguir esse aspecto, vale a pena referir - o que ademais é sabido de todos - que os Estados Unidos dominam a OMC. Pretende-se apenas sublinhar dois aspectos relevantes desse acordo, a saber, a) o acordo prevê medidas na direção de um maior intercâmbio, englobando a análise e a difusão de informações culturais entre os países e b) os países signatários arrecadam para si compromisso na promoção da "conscientização pública sobre as diversas formas de cultura" (YODA, 2006c). Esse segundo aspecto é relevante manter como um enquadramento geral na pesquisa sobre a cultura, sobre as culturas ditas populares e, no presente caso, sobre a literatura/poesia de transmissão oral.

Não se quer aqui, ao usar a expressão diversidade cultural, "chover no molhado", ou, ao contrário, ao defendê-la, "dar murro em ponta de faca". Chama-se meramente a atenção para o enquadramento epistemológico e político que há aí implicado, importante de ser ressaltado no momento da fundamentação de uma pesquisa que envolva a questão das diversidades culturais. Trata-se não apenas do fazer, mas do ter critério ao fazer, seja o que for, no âmbito da cultura - como, de resto, em qualquer âmbito do humano. Com isso, a pesquisa também é posicionada claramente no contexto de avaliação das distintas iniciativas de discussão, de pesquisa, análise e promoção da dita diversidade cultural, não só na Bahia, no Nordeste ou no Brasil, mas também em âmbito global. Somos uma sociedade multi, inter, transculturada - híbrida. Não há mais sentido em procurar a fonte, a influência, a origem.

E, como viu-se acima, há uma distinção entre cultura como identidade - enquanto diversidade cultural - e entre cultura como produto destinado ao consumo. Claro que pode, por vezes, ocorrer uma intersecção - o produtor de cultura ocasionalmente se especializa, vê a sua inserção na sociedade de consumo como uma alternativa de subsistência -, mas essa não é a regra geral no âmbito das chamadas culturas populares, subalternas, não-eruditas e nãomassivas. Parece que aqui há relativo consenso.

Os processos das transferências culturais em nosso país receberam, claro, atenção por parte das várias disciplinas, a partir de variados pontos de vista. Na literatura - nosso âmbito de atuação, lembramos - a constatação, pelo romantismo, no séc. XIX, da questão do "mimetismo cultural" foi uma tentativa de lidar com isso, ao mesmo tempo em que se procurava erigir uma possível identidade nacional a partir da literatura (cf. VENTURA, 1991). Na segunda metade do séc. XIX, difundiu-se o conceito positivista (e europeu) de literatura nacional, o qual postulava três exigências para a existência de uma literatura nacional, notadamente: a) unidade; b) homogeneidade e c) sistematicidade dentro de um espaço nacional (cf. POLAR, 2000a, p.124; v. tb. CANDIDO, 1997, p.23-37). Neste 
processo, os esforços orientadores eram voltados no sentido de erigir uma alta literatura que simultaneamente tivesse afinidade com o espírito nacional então em formação. Apesar de, num primeiro momento, ser contemplada a cultura indígena de maneira superficial, as culturas afro-brasileiras ficaram excluídas desse incipiente processo de fundação da identidade nacional. Acerca disso, há que se ver as diversas polêmicas travadas na segunda metade do séc. XIX, abordadas de forma magistral por Ventura (1991).

A postura antropofágica, sugerida por Oswald de Andrade (1990 [1928]), em inícios do séc. XX, foi uma resposta a esta questão do séc. XIX; mais próximo de nós, a proposição dos termos "entre-lugar" e "hibridismo", por Silviano Santiago (1978), a partir da análise dessa questão no âmbito da literatura e da cultura latino-americanas foi outra tentativa de expandir a análise de fatos literários para os âmbitos culturais da identidade e da diversidade. - Com respeito ao âmbito literário, a premissa da identidade nacional calcada numa língua única levou a que, por muito tempo, se dispensasse grande valor à cultura chamada erudita, que também funcionava como caráter diferenciador étnico-social.

$\mathrm{Na}$ intersecção entre estudos literários, sociologia, antropologia e história cultural, surge, já em meados da primeira metade do séc. XX, na América Latina, uma série de trabalhos que constatam um desencaixe no tratamento dessas questões das transferências e influências culturais. Procura-se, neste momento, por novas alternativas para perguntas sobre a identidade em meio à diversidade cultural, tais como, em Cuba, Fernando Ortiz, com a proposta da "transculturação" (cf. RAMA, 1987); no Brasil, Gilberto Freyre, com a “democracia racial” (cf. MARTINEZ-ECHAZÁBAL, 1996). Essas propostas têm em comum a passagem de um paradigma racial para uma visão étnico-cultural. Mesmo assim, é preciso assinalar que esse desenvolvimento não é linear, de forma que podem ocorrer retrocessos.

A chegada da disciplina dos estudos culturais aos meios universitários brasileiros iniciou, num primeiro momento, uma saudável discussão acerca do papel da cultura no âmbito social. Por outro lado, no início da última década do séc. XX, na área da literatura, estabeleceu-se certa polarização entre a ampliação do campo de estudos e a manutenção do campo da forma como estava se cristalizando na universidade brasileira (cf. MOREIRAS, 2001). As duas posições - a rejeição desses estudos mais ampliados por certa parcela dos docentes e pesquisadores, ou a defesa, por parte de outra parcela do meio universitário, da ampliação do conceito de texto e textualidade para o âmbito sociocultural e político, englobando outras formas de suportes e mídias - são elas mesmas índices de posturas epistemológicas distintas, com conseqüências distintas também para o sistema educacional e formacional das novas gerações. Dizendo-o de outra forma: ao se recusar a ampliação do 
campo, ao se desconsiderar as novas tendências no âmbito da pesquisa, menospreza-se toda uma série de iniciativas - em termos de proposições de currículos - colocadas em movimento justamente desde meados da última década do séc. XX, sejam elas desde as proposições da Unesco (por exemplo, dos chamados "pilares da educação para o séc. XXI", que são ratificados em documentos oficiais, tais como os Parâmetros Curriculares Nacionais, dentre outros).

Volta e meia ouve-se, nos corredores dos departamentos de letras, que os estudos culturais estariam se esgotando. Isso certamente tem certa pertinência, pois já conhecemos esse processo de hipercomplexificação que acontece quando da delimitação de um novo campo de investigação ou de uma nova disciplina. Trata-se, nesse aspecto, de algo semelhante com o que aconteceu, por exemplo, com a semiótica no séc. XX - não por acaso uma disciplina que se propunha à análise do âmbito cultural. No entanto, não se deveria rejeitar uma sorte de estudos mais aberta para o âmbito cultural, simplesmente pelo fato de que essa postura epistemológica ainda não reverteu para um benefício mais amplo em termos de tratamento da diversidade e da alteridade, seja local e regionalmente, seja ainda nacional e globalmente - a tal ponto de que seja necessária uma convenção da Unesco sobre a questão.

A pesquisa de aspectos das culturas populares, das culturas afro-brasileiras, das culturas ameríndias - cujos legados, em grande parte, são transmitidos de forma oral, não deveria servir à mera descrição formalista, à procura das fontes e das influências, ao lema do "registre antes que desapareça", à folclorização, à demarcação de "reservas culturais primitivas", como tantas vezes vemos sendo feito, inclusive nos materiais didáticos que servem à formação dos futuros cidadãos. Trata-se, acima de tudo, de ter uma postura de abertura. E não esquecer de onde falamos enquanto pesquisadores: de dentro da tradição ocidental, enquanto representantes de uma instituição social - de dentro da escola ou da universidade, instituições predominantemente iluministas. O princípio mais geral é caro: respeito à diferença representa igualdade de oportunidades; proporcionar igualdade de oportunidades significa inclusão e fomento de possibilidades de escolha a todos. - Esse é o enquadramento geral de nossa pesquisa. Vejamos agora os aspectos específicos a partir do ponto de mirada da teoria da literatura.

\section{Oralidade e poesia}

$\mathrm{Na}$ área da literatura, num vetor temporal, coloca-se a Grécia Antiga como princípio demarcador. Esse pressuposto já é ele mesmo um índice de, pelo menos, três questões 
problemáticas do ponto de vista de onde falamos: a) remete a uma pretensa homogeneidade para questões de origem, i. e., somos ocidentais; portanto, temos que começar a refletir a partir do princípio da civilização e da cultura ocidentais; b) não somos tão ocidentais quanto poderíamos supor, porque, nos cursos de letras, as disciplinas de literatura, cultura e língua gregas foram excluídas, colocando-se no lugar delas as relativas à literatura, cultura e língua latina - e destas os discentes, de forma geral, não se apetecem muito, contrariamente ao observável com relação àquelas -; e c) esquecemos os substratos culturais e literários nãoocidentais, representados exatamente pelos dois grandes conjuntos das culturas ameríndias e das culturas afro-brasileiras - raros são os departamentos de letras que oferecem disciplinas relativas a essas literaturas, culturas e línguas, simplesmente porque quase que não existem docentes e pesquisadores para tal - a formação destes pesquisadores e docentes a recém começou. Verifica-se aqui um imbróglio epistemológico, senão uma sensação de coisas fora do lugar, de forma que, ao tratar da questão da poesia da tradição oral, realmente se tem que começar pela Grécia Antiga, apesar disso poder ser altamente questionável.

Os gregos, tal como certamente outras culturas, possuíam, antes mesmo de dominarem a escrita, uma cultura literária bastante rica. Narrativas mitológicas, relatos de aventura, canções ritualísticas e profanas, além de regras de conduta, eram transmitidas de forma oral, de uma geração para a outra.

Sabe-se que uma forma eficaz de ativar a memória - fundamental nesse processo de armazenamento e transmissão dos textos - é o recurso à metrificação e ao ritmo. Essas duas variáveis caracterizam o que chamamos de verso, em oposição à prosa que, por sua vez, não possui tais características. Tanto o ritmo - a cadência regular - quanto a extensão - em geral medida pelo número de sílabas - dos versos é sempre culturalmente marcada. Neste sentido, o ouvinte, ao ouvir os primeiros versos, já prefigura um determinado tipo de texto ou tema. Além disso, cada tipo de contexto situacional também pode, ao longo do tempo, ensejar certas expressões bem definidas - uma canção fúnebre terá versos com ritmo e extensão distintos dos de uma canção profana, de festa, por exemplo.

Além dessas duas características do verso, ainda temos, como coadjuvante para a ativação da memória, a melodia. No verso, a melodia pode meramente lançar mão de recursos lingüísticos, mas a memória é mais beneficiada quando os versos são acompanhados por instrumentos musicais e, mais ainda, quando se acresce a dança. O conjunto de versos é denominado de poema, em oposição à prosa - esta, por sua vez, é o registro da fala sem as características do verso. Quando o poema é acompanhado da melodia musical, ele é denominado de canção. No que concerne à memória, um poema é mais facilmente 
memorizado do que um texto em prosa; por sua vez, a canção é ainda mais facilmente memorizada do que um poema.

No caso da poesia grega antiga, há ainda que se levar em conta que o sistema de marcação rítmica e melódica era bastante distinto dos sistemas poéticos conhecidos das atuais línguas neolatinas. A rima, por exemplo, não era usada na língua grega antiga - o que se manteve também na poesia em língua latina, por conta, principalmente, da declinação das palavras (algo que a maioria das línguas neolatinas não manteve). Além da inexistência da rima, a estruturação do verso não era feita pela contagem das sílabas, subdivididas em fortes e fracas - o sistema quantitativo -, mas em sílabas longas e breves - sistema qualitativo -, demarcado em pés, o que dava à declamação em voz alta uma musicalidade muito própria algo que vagamente podemos perceber hoje, por exemplo, no canto gregoriano e nas ladainhas.

Figura importante para a poesia grega, antes do período de domínio da escrita, era o aedo - espécie de poeta-cantor que viajava de um local para o outro, levando a bagagem poética da tradição grega em sua memória. Neste sentido, chega-se a discutir, entre os especialistas da cultura grega antiga, que os textos fundadores da literatura ocidental (escrita) - os poemas épicos da Odisséia e da Ilíada, comumente atribuídos a Homero, na verdade, seriam produtos do trabalho dos aedos ao longo de séculos de literatura oral; antes, portanto, do domínio e da difusão do uso da escrita. - Neste sentido, a figura do aedo possui certa equivalência com a do rapsodo - recitador de poemas, também da tradição grega - e com a do griot, ou griô, conhecido de certas culturas africanas, como veremos abaixo.

O filósofo grego Aristóteles (1996) é um dos que vai se dedicar, em sua Poética, à questão da poesia, do poema e indiretamente à oposição entre escrita e oralidade. Ele identifica três tipos de poesia que seriam socialmente relevantes dentro de seu sistema filosófico, a saber, a poesia trágica, a poesia épica e a poesia lírica. Na caracterização desses três gêneros, utiliza o conceito de mímesis, desenvolvido por seu professor, o filósofo Platão (1997). Esse termo comumente é traduzido, quando falamos do sistema platônico, por imitação - mimetismo sendo, por extensão, processo de cópia de algum original anterior. No caso do pensamento platônico, a imitação da poesia ocorria em terceiro grau: em primeiro lugar estava o "mundo das idéias"; em segundo, o "mundo real", considerado uma cópia/imitação deste "mundo das idéias"; e, em terceiro, vinha a poesia, que, segundo Platão, procurava copiar/imitar o "mundo real" - por conta disso é que o sistema platônico vê com maus olhos a poesia, como forma que afastaria o ser humano da pretensa verdade do mundo das idéias. Note-se, ainda com respeito ao sistema platônico, que poesia pode significar, por 
extensão, todo o âmbito das artes representacionais. Por outro lado, quando falamos de Aristóteles, nos aproximamos mais do conceito de representação, assim como o conhecemos do séc. XX, enquanto capacidade da linguagem de presentificar alguma coisa, enquanto simbolização.

No sistema peripatético, a poesia é classificada com respeito à capacidade que ela tem de representar o ser humano ideal, i. e., o ser humano ideal para uma sociedade, uma pólis grega ideal. Neste sentido, nem Platão, nem Aristóteles deixaram de identificar o valor ético e político, além, claro, do valor estético, envolvido na questão cultural - algo que o séc. XX convencionou chamar de identidade cultural (esse conjunto, em alguns contextos teóricos, vem sendo chamado também de ethos): conjunto de elos ético-morais, sócio-políticos e estético-culturais de pertencimento a uma determinada comunidade. Então, para Aristóteles, a poesia trágica é a mais elevada, porquanto ela representar o ser humano de forma melhor do que ele é na realidade, em oposição à poesia cômica, por exemplo, que apresenta o ser humano pior do que ele é, tornando-o risível, caricaturizando-o, por assim dizer. A poesia trágica, portanto, era feita para ser representada no palco e era vivenciada pela coletividade da pólis. Aristóteles ainda se referiu, na Poética, à poesia épica: poesia, porque estruturada sob a forma do sistema de versificação da tradição oral grega descrita acima, mas de característica essencialmente narrativa. A poesia épica também é considerada elevada pelo filósofo, por trazer as narrativas míticas fundadoras da identidade coletiva que se colocava acima da diversidade das pólis gregas, em oposição às outras culturas com as quais mantinham contato - tais como, egípcios, fenícios, persas -, por meio, principalmente, das suas atividades comerciais pelo Mediterrâneo. A poesia lírica, por ser mais próxima da vivência prosaica do cotidiano, não foi abordada por Aristóteles, apesar de ter sido referida. - Conjecturou-se acerca da possível existência de uma segunda parte da Poética, de Aristóteles, a qual se teria perdido ou, segundo o semioticista e escritor italiano Umberto Eco, em seu O nome da rosa, teria sido guardada a sete chaves em algum mosteiro medieval, por tratar, além da poesia lírica, da poesia cômica e do riso - estes considerados perniciosos e daninhos ao estoicismo pregado pelo cristianismo. Já o sistema platônico, que pregava a pretensa periculosidade da poesia, é mais afim da moral cristã, o que permitiu que o mundo ocidental fosse basicamente platônico até o renascimento.

No estudo das expressões poéticas de transmissão oral, a tradição grega antiga é importante como um ponto de partida de reflexão do âmbito especificamente estético enquanto conjunto de regras que regem um sistema de composição e recepção de produtos culturais - no nosso caso, o poema. Do ponto de vista metodológico, a tradição grega, 
brevemente descrita acima, pode ser considerada um ponto inicial, a partir do qual se pode começar a refletir didaticamente, pois que, como vimos, esta tradição é relativamente contemplada pelos currículos dos cursos superiores de letras.

\section{Fala e escrita}

A presente pesquisa pretende se aprofundar também no tratamento da questão da oposição entre fala e escrita. Esta oposição, desde o pensamento pós-estruturalista, especificamente desde os trabalhos de Jacques Derrida (1995; 1997), sabemos ser importante para a descrição de impasses característicos ao modo de pensar e ver o mundo propriamente ocidental, para a qual, ademais, já havia chamado atenção o filósofo Martin Heidegger, de quem Derrida foi aluno. Desde Derrida, fala-se mais enfaticamente em desconstrução dos centros inquestionáveis do ocidente. Para Derrida, a história do ocidente é marcada profundamente por uma sucessão de centros inquestionáveis - tais como, consciência, deus, homem, cultura, verdade -, que presidem e são responsáveis pela idéia de centro unificador do mundo. Tal forma de pensamento transcendental e essencialista é denominada de "logocentrismo". Segundo essa concepção logocêntrica de ver o mundo, o centro é afirmado pelo não-valor de seu termo oposto: consciência/loucura, deus/diabo, homem/mulher, cultura/natureza, verdade/mentira, espírito/corpo, fala/escrita.

Se a noção de "logocentrismo" permite uma ruptura com os significados universais, a determinação, dentro do discurso das ciências humanas, da existência de verdades calcadas em dados na natureza, e não em constructos da ordem cultural, permite a fixação e compreensão da existência do "etnocentrismo", que foi e é o responsável pela idéia da superioridade de uma cultura sobre a outra, como por exemplo, da superioridade da cultura européia sobre a cultura dos demais continentes, ou ainda, da superioridade da cultura letrada e erudita sobre as culturas de tradição oral e ágrafas.

A terceira noção proposta pelo filósofo da desconstrução é denominada de "fonocentrismo" e consiste no questionamento da centralidade da fala sobre a escrita, sendo simultaneamente um aspecto do logocentrismo. Ao constatar a primazia da fala sobre a escrita - no ocidente a escrita é compreendida como mera representação da fala -, Derrida ainda chama a atenção para outros pares de oposições, cujo primeiro termo possui a primazia, tais como, presença/ausência, presente/passado, natureza/cultura. A primazia da fala dá-se por conta de se pressupor a presença do falante; já a escrita seria apenas necessária num vetor temporal ou espacial de ausência do interlocutor. Daí que é necessário supor uma lógica de 
suplementariedade para essas oposições, já que não é possível determinar uma origem absoluta para o significado: o significado decorre sempre de relações e não de essências isoladas.

Essa lógica da suplementariedade proposta pelo filósofo permite ver os pares de oposições binários não como excludentes, como antíteses, mas antes como elementos inclusivos. Neste sentido, Derrida acabou por criar uma teoria da diferença que aponta para a abertura do próprio discurso, enfatizando que o significado é sempre móvel, múltiplo e ilimitado. As consequiências da postura descontrutivista para a presente pesquisa, ao invés de apontarem a origem, a fonte ou a essência de determinada cultura, estética ou textualidade poética, podem descortinar a lógica da rede de significados patente ao período de interconexão informacional em âmbito global em que vivemos. Em outras palavras, explicitando-o no sentido das conseqüências desta postura para a presente pesquisa, trata-se de compreender, entender o funcionamento dos textos poéticos encontrados na pesquisa de campo junto aos poetas-produtores. A descrição, caso necessária, será no sentido de descrever a forma como os signos funcionam nos poemas, num primeiro momento, para depois chegar à elucidação do estado geral dos signos, rumo à história social e cultural.

\section{A letra e a voz}

No que concerne ao par que nos interessa aqui em nossa pesquisa - oralidade e escrita -, resta interessante referir o episódio considerado por Cornejo Polar (2000b, p.227 e 228) como o "grau zero" da literatura latino-americana. Trata-se do diálogo de Cajamarca, travado entre o imperador inca Atahualpa e o padre espanhol Valverde, em 1532, em algum ponto onde fica o atual Peru. Polar considera este diálogo - marcado por "incomunicação absoluta" (um dos interlocutores é morto) - como o início simbólico do que ele denomina de " "grau zero' da relação entre uma cultura oral e outra escrita" (POLAR, 2000b, p.227). A cultura oral é a do inca, a cultura escrita é o latim do padre e o espanhol do conquistador. Na elucidação desse impasse, o autor defende um "conceito ampliado de literatura", que inclua a) tanto o horizonte da recepção - a recepção do texto escrito provindo de uma outra cultura - pelos povos autóctones; b) quanto contemple de forma séria a questão da oralidade - no âmbito da distinção entre a "voz" e a "letra". Segundo o autor, a razão principal para um conceito ampliado de literatura

[...] tem a ver com algo mais importante que continua marcando até hoje a textura mais profunda das nossas letras e de toda a vida social da América Latina: com o destino histórico 
de duas consciências que desde o seu primeiro encontro se repelem pela matéria lingüística em que se formalizam, o que pressagia a extensão de um campo de enfrentamentos muito mais profundos e dramáticos, mas também a complexidade de densos confusos processos de imbricação transcultural (POLAR, 2000b, p.221).

Essa "textura mais profunda" das letras e essa "repulsa lingüística" das duas consciências dizem respeito

[...] a uma pertinaz preocupação latino-americana: a da pertinência (ou não) da linguagem que se diz a si mesma, que bem se pode entender como uma variante da obsessão primária, relativa ao reconhecimento de uma identidade em cujas fibras mais íntimas sempre aparece, como força desestabilizante, mas não necessariamente negativa, a figura do outro (POLAR, 2000b, p.222).

Levar em conta esta preocupação apontada por Polar (2000b) - a da pertinência (ou não) da linguagem -, coloca a pesquisa dentro do contexto conhecido como estudos póscoloniais, já que leva em conta esses processos de imbricamentos culturais como resultado de um processo histórico que não cessou ainda.

Falamos, acima, das figuras do rapsodo - o poeta-orador-recitador - e do aedo - o poeta-cantador -, ambos importantes na cultura grega antiga anterior ao domínio da escrita. Afirmamos que eles possuíam certa equivalência com a do griot, ou griô, conhecido de certas culturas africanas. Assim como o aedo e o rapsodo, o griô viajava de cidade em cidade, recitando, contando e cantando histórias. $\mathrm{O}$ estabelecimento das convergências, divergências e diálogos destas duas entidades, provindas de duas tradições importantes para o conjunto da identidade brasileira, coloca-se, portanto, como um dos objetivos a ser perseguido. Nesta sistematização, outros protagonistas da tradição poética também poderão ser contemplados, tais como, a) as figuras do cordelista, do embolador e do repentista; b) o surgimento de rimadores da cena rap e hip-hop, igualmente oriundos das camadas populares e tributários da tradição oral, especialmente da tradição da embolada. Nesse imbricamento suplementar e rizomático, nesses processos de hibridização (CANCLINI, 2000), transculturação (RAMA, 1987) e marcados por heterogeneidade (POLAR, 2000b) em que, de forma geral, as culturas populares se encontram, sob a influência da cultura erudita e das culturas massificadas, não se trata, como já foi afirmado, de procurar a origem ou a influência, mas antes de compreender os fatos culturais estético-poéticos, o produtor-poeta, bem como seu público ouvinte-leitor como em processo mesmo.

\section{Questões éticas da pesquisa}


Ao lidar com levantamento de campo - necessário neste tipo de pesquisa, por conta do motivo óbvio da produção não ser escrita e, quando escrita, raramente divulgada -, é necessário levar em conta certos pressupostos éticos e metodológicos específicos, normalmente não-usuais em pesquisas acadêmicas na área de literatura. Neste aparte entram quesitos mais comumente tratados pela história oral e pela antropologia, que, de forma mais recorrente, fazem uso da metodologia da entrevista semi-estruturada e da conversa informal com os informantes - estes também chamados de nativos.

Neste sentido, os trabalhos de Alessandro Portelli (1997a; 1997b) podem ser de grande serventia, na medida em que ele, apesar de falar especificamente da história oral, elucida importantes aspectos a serem levados em consideração em pesquisas que envolvam a oralidade. Dentre os aspectos que podem interferir no desenrolar da pesquisa, pode-se citar: a recusa à entrevista; o afloramento de visões mútuas distorcidas (entre pesquisador e entrevistado); preconceitos; visões estereotipadas; simplificações, etc.

Portelli chama a atenção para o fato de que "uma entrevista é uma troca entre dois sujeitos: literalmente uma visão mútua" (1997a, p.11). Essa condição de reciprocidade e de abertura mútua entre pesquisador e pesquisado é uma das condições da possibilidade desse tipo de pesquisa, no sentido de uma comunicação que seja menos distorcida. No entanto, o autor aponta para o fato de que a igualdade não pode meramente ser desejada, já que ela não depende somente da boa vontade do pesquisador, mas antes das condições sociais. Neste sentido, Portelli inclui, de saída, importante aspecto que é objeto da própria pesquisa em si: o reconhecimento da diversidade social, cultural e/ou política, já que necessariamente ocorre a constatação, entre os dois lados envolvidos, da diversidade em indivíduos que não pertencem a planos sociais iguais. Esta dificuldade espera-se ser minimizada na medida em que a presente pesquisa vai atuar em uma área cuja população já está relativamente acostumada com a presença de pesquisadores, notadamente na Chapada Diamantina, na Bahia. Nesta área, já há importantes projetos em fase de execução, por exemplo, nas áreas de geografia, geologia, história ambiental, dentre outros.

Um outro dado relevante referido por Portelli (1997b) justamente diz respeito a aspectos tratados acima. Senão, veja-se:

Parece se temer que uma vez abertos os portões da oralidade, a escrita (e a racionalidade junto com ela) será varrida como que por uma massa espontânea incontrolável de fluídos, material amorfo. Mas esta atitude cega-nos para o fato de que nosso temor respeitoso de escrever tenha distorcido nossa percepção de linguagem e comunicação até o ponto em que não mais se entendem quer a oralidade quer a própria natureza da escrita (PORTELLI, 1997b, p.27). 
Dessa forma, a pesquisa da literatura de cunho oral pode ser proveitosa, desde que se chegue a um patamar que não seja mutuamente excludente em relação à escrita, levando em conta as características e funções específicas de cada uma, bem como as convergências, o que necessariamente também requer aparato interpretativo específico.

\section{Conclusão}

De forma relativamente esquemática, este é o enquadramento específico - a partir do ponto de vista da teoria da literatura - da pesquisa sobre a poesia de tradição oral.

A cunho de conclusão, elenca-se aspectos de ordem geral, reportando a efeitos sentidos na mídia (YODA, 2006a), com respeito à realização, em setembro do ano de 2006, em Brasília, do I Encontro Sul-Americano das Culturas Populares e do II Seminário de Políticas Públicas para as Culturas Populares. Segundo o que foi veiculado, está-se avançando um pouco, tentando colocar em prática o que prevê a Constituição Federal de 1988, em seu Art. 216, a saber: "O Estado garantirá a todos o pleno exercício dos direitos culturais e acesso às fontes da cultura nacional, e apoiará e valorizará a manifestação e a difusão das manifestações culturais" (BRASIL, 2008, p.42).

Mas certamente muito há que ser feito ainda. E aqui vale o que foi dito no início deste trabalho. Quando se vai fazer algo, seja o que for e independente do âmbito em que for feito, diria que vale uma premissa que é conhecida de ouvido: "fazer bem feito ou fazer mais ou menos, dá o mesmo trabalho". Com isso, reporta-se à necessidade, reafirmada na repercussão dos eventos acima listados (YODA, 2006b), de ter critérios claros e bem definidos para os investimentos públicos em cultura, investimentos que certamente precisam ser incrementados, mas que acima de tudo precisam reverter em algo de útil para a coletividade.

Dessa forma, para além da mera canibalização e espetacularização promovida pela cultura de massa com respeito às culturas populares (VALENTE, 2006), não se pode esquecer que há uma grande diferença entre fazer cultura por pertencimento e fazer cultura por exercício mercadológico (BRANDT, 2005, p.21).

Além da Constituição Federal, também

A Declaração Universal dos Direitos Humanos prevê o direito à cultura como um direito fundamental e inalienável do ser humano, mas [...] uma declaração não é suficiente para oporse ao complexo universo de interesses e forças sobre-humanas em que se encontram as culturas do mundo, como presas em uma tempestade no meio do oceano (SEGÓVIA, 2005, p.88). 
Neste sentido, para além da mera descrição, canibalização mercadológica ou folclorização, pretende-se, com a presente pesquisa, contribuir para a construção de uma sociedade mais justa e democrática, de uma sociedade que tenha consciência de sua diversidade, no sentido do respeito mútuo entre as diferenças. A fala do Ministro Federal de Cultura bem pode expressar isso:

[...] sempre pensei em cultura como uma obra aberta, como um software de código aberto. As trocas com o que é dos outros, a antropofagia cultural constante fazem parte das vitalidades das culturas, e as possibilidades de trocas livres devem ser preservadas contra qualquer tentativa de imposição (GIL, 2005, p.9).

\section{Referências}

ANDRADE, Oswald de. Manifesto antropófago. In: BELLUZZO, Ana Maria de Moraes. (Org.). Modernidade: vanguardas artísticas na América Latina. São Paulo: Fundação Memorial da América Latina/UnesP, 1990, p. 268-73. Originalmente publicado no número 1 da Revista de Antropofagia, de São Paulo, em 1928.

ARISTÓTELES. Poética. São Paulo: Nova Cultural, 1996, p. 31-60. Col. Os pensadores.

BRANDT, Leonardo. Dimensões e perspectivas da diversidade cultural no Brasil. In:

(Org.). Diversidade cultural: globalização e culturas locais: dimensões, efeitos e perspectivas. São Paulo: Escrituras/Instituto Pensarte, 2005, p. 21-56. Col. Democracia cultural, 1.

BRASIL. Constituição da República Federativa do Brasil. (1988). Texto consolidado até a Emenda Constitucional n. 53 de 19 de dezembro de 2006. Brasília: Senado Federal/Secretaria Especial de Editoração e Publicações/Subsecretaria de Edições Técnicas, 2006.Disponível:

http://www.ancine.gov.br/media/Constituicao_Federal_EC53.pdf>. Acesso em: 28 abr. 2008.

CANCLINI, Néstor García. Noticias recientes sobre la hibridación. In: HOLLANDA, Heloisa Buarque de; RESENDE, Beatriz. Artelatina: cultura, globalização e identidades. Rio de Janeiro: Aeroplano, 2000, p. 60-82.

DERRIDA, Jacques. A escritura e a diferença. Trad. SILVA, Maria Beatriz M. Nizza. 2. ed. São Paulo: Perspectiva, 1995.

DERRIDA, Jacques. A farmácia de Platão. 2. ed. São Paulo: Iluminuras, 1997.

GIL, Gilberto. Prefácio. In: BRANDT, Leonardo. (Org.). Diversidade cultural: globalização $e$ culturas locais: dimensões, efeitos e perspectivas. São Paulo: Escrituras/Instituto Pensarte, 2005, p. 7-11. Col. Democracia cultural, 1.

HEIDEGGER, Martin. Identidade e diferença. Trad. STEIN, Ernildo. 2. ed. São Paulo: Duas Cidades, 1978. 
MOREIRAS, Alberto. A exaustão da diferença: a política dos estudos culturais latinoamericanos. Belo Horizonte, UfMG, 2001.

PLATÃO. Fedro. Lisboa: Ed. 70, 1997.

POLAR, Antonio Cornejo. A literatura latino-americana e suas literaturas regionais e nacionais como totalidades contraditórias. In: $O$ condor voa: literatura e cultura latino-americana. Organização: VALDÉS, Mario J. Trad. CARVALHO, Ilka Valle de. Belo Horizonte: Ed. UfMG, 2000a, p. 123-132.

POLAR, Antonio Cornejo. O começo da heterogeneidade nas literaturas andinas: voz e letra no "diálogo" de Cajamarca. In: $O$ condor voa: literatura e cultura latinoamericana. Organização: VALDÉS, Mario J. Trad. CARVALHO, Ilka Valle de.Belo Horizonte: Ed. UfMG, 2000b, p. 219-285.

PORTELLI, Alessandro. Forma e significado na História Oral: a pesquisa como um experimento em igualdade. Proj. História, v. 14, p. 7-24, fev. 1997a.

PORTELLI, Alessandro. O que faz a história oral diferente. Proj. História, v. 14, p. 25-39, fev. 1997b.

RAMA, Ángel. Transculturación y género narrativo. In: La ciudad letrada. 3. ed. México: Siglo XXI, 1987.

SANTIAGO, Silviano. O entre-lugar do discurso latino-americano. In: Uma literatura nos trópicos. São Paulo: Perspectiva, 1978, p. 11-28.

SEGÓVIA, Rafael. As perspectivas da cultura: identidade regional versus homogeneização global. In: BRANDT, Leonardo. (Org.). Diversidade cultural: globalização e culturas locais: dimensões, efeitos e perspectivas. São Paulo: Escrituras/Instituto Pensarte, 2005, p. 82-90. Col. Democracia cultural, 1.

VALENTE, Jonas. Seminário nacional discutiu fomento às culturas populares. Disponível em: <http://www.culturaemercado.com.br/setor.php?setor=4\&pid=977>. Acesso em: 14 out. 2006. Originalmente publicado em Carta Maior.

VENTURA, Roberto. Estilo tropical: história cultural e polêmicas literárias no Brasil (18701914). São Paulo: Cia. das Letras, 1991.

YODA, Carlos Gustavo. Culturas populares enfrentam dificuldades para chegar na mídia. Disponível em: <http://www.culturaemercado.com.br/setor.php?setor=4\&pid=991>. Acesso em: 14. out. 2006a. Originalmente publicado em Carta Maior.

YODA, Carlos Gustavo. MinC lança projeto para incentivar tradição oral. Disponível em: <http://www.culturaemercado.com.br/setor.php?setor=4\&pid=996>. Acesso em: 14. out. 2006b. Originalmente publicado em Carta Maior.

YODA, Carlos Gustavo. Unesco ainda precisa resistir às pressões dos EUA. Disponível em: <http://www.culturaemercado.com.br/setor.php?setor=4\&pid=1007>. Acesso em: 9 out. 2006c. Publicado originalmente em Carta Maior. 